\title{
in crime and criminal justice
}

No. 463 November 2013

\section{Oral language competence \\ and restorative justice processes: Refining preparation and the measurement of conference}

Foreword | Restorative justice conferencing for young offenders is a legislated response to youth offending, which has been in place in all Australian states and territories for nearly two decades. Restorative justice conferences are meetings between young offenders, their victims and supporters to discuss the offence, its impact and what the young person can do to repair harms caused by the offending behaviour. There is now a substantial body of research that has examined the impact restorative justice processes have on participants (eg how young offenders and victims judge the process). Results are largely positive, showing that participants view restorative justice processes as fair and they are satisfied with outcomes. Given the highly conversational nature of restorative justice conferencing processes however, this paper reviews research on oral language competence and youth offending. It raises questions about the need to refine preparatory work with young offenders and victims, to better understand young offenders' capacities to effectively communicate in conference processes. It suggests that improved preparation (where language impairments in young offenders are identified and addressed) will lead to better outcomes for young offenders and victims.

Adam Tomison

Director outcomes

\section{Hennessey Hayes and Pamela Snow}

For nearly two decades, restorative justice responses to youth offending have been in place in all Australian states and territories. During this time, a vast amount of research on restorative justice processes and their impact on participants has amassed. Results consistently demonstrate that participants in restorative justice processes report positive experiences and regard their justice process as fair. Less is known, however, about the impact that restorative justice processes have on further youthful offending, as results from research are highly inconsistent (Hayes 2007, 2006, 2005; Smith \& Weatherburn 2012). What is also less clear is the degree to which restorative justice processes are in fact restorative (eg for the offender, a restored sense of self-worth and for the victim, a restored sense of security and dignity). Some of the uncertainty around the restorative potential of restorative justice processes may centre on the oral language competencies of young offenders and their often limited ability to both infer others' and express their own emotion in highly conversational and emotionally charged processes. Recent Australian research on the oral language skills of young offenders shows that one in two has a clinically significant, yet previously undiagnosed language impairment (Snow \& Powell 2011a, 2008). 
In this paper, literature on language competence and restorative justice is reviewed to explore the links between oral language competencies, emotional communication and restorative justice process 'success'. The need for more systematic research in the area of oral language competence (OLC) and restorative justice is highlighted and how such research can inform the enhancement of restorative justice practice and improve process outcomes is suggested.

\section{Restorative justice processes in Australia}

Restorative justice responses to offending by youths have had a legislative basis in Australia for nearly two decades. Restorative justice is defined most commonly as

... a process whereby parties with a stake in a specific offence collectively resolve how to deal with the aftermath of the offence and its implications for the future (Marshall 1999: 5).

Looking across international jurisdictions, it can be seen that restorative justice takes on many different forms, ranging from sentencing circles and victim-offender mediation in North America and the United Kingdom, to conferencing in New Zealand and Australia (Raye \& Roberts 2007). Restorative justice conferencing in Australia is principally reserved for young offenders; however, some jurisdictions are using conferencing in response to some forms of adult offending. For example, adult sexual offenders may be referred to a restorative justice conference in South Australia (Daly 2002). Also, in New South Wales, a Local Court may refer eligible adult offenders to forum sentencing, where offenders, victims, supporters and police discuss the offence and its impact, as well as what the offender can do to repair harm (Hart \& Pirc 2012). Furthermore, the Restorative Justice Unit of NSW Corrective Services runs post-sentence victim-offender conferences for adult offenders (Milner 2012).

The first legislated conference scheme emerged in South Australia in 1994, following a police-run conferencing trial in Wagga Wagga, New South Wales. By 2003, all Australian states and territories had enacted legislation to support the use of conferencing for young offenders. Most jurisdictions have adopted the 'New Zealand model' where civilian staff facilitate the conference process. However, the Northern Territory, Tasmania and the Australian Capital Territory have adopted dual models where both civilian staff and police facilitate conferences (Maxwell \& Hayes 2006).

Conferences typically progress through three phases - introduction, storytelling and agreement negotiation. The conference convenor or facilitator opens the conference with general introductions and a summary of what the conference is meant to achieve and what participants are expected to do. Next, the young person is asked to account for their offending behaviour. In telling their story, young offenders are asked to relate how they became involved in the offence and what they were thinking and feeling at the time. It is expected that the young person will acknowledge the harm that they have caused the victim.

Victims are then asked to describe how the offence has affected them. For example, victims often highlight how the offence has affected them emotionally, physically and materially. Supporters (eg parents of young offenders and partners of adult victims) then offer additional comments. Convenors then return to the young person and ask how the victim's story makes them feel. It is at this point that young offenders often admit that the victim's story helped them to appreciate the full impact of their behaviour. Furthermore, some offenders at this point offer apologies to their victims.

The conference concludes with a discussion of what the young person can do to make up for the offending, to repair the harms they have caused. Convenors first ask the young person to offer suggestions. These are then discussed among all participants with the aim of arriving at a consensus about what the young person will do to complete the agreement. Common agreements include a verbal and/or written apology, a commitment not to reoffend, work for the victim or the community, or monetary restitution (Hayes 2006).

\section{The conversational nature of restorative justice processes}

The previous section describes restorative justice as a process that requires young offenders to effectively engage in a conversation about their wrongdoing and ways of repairing harms they have caused. As such, the restorative justice process draws heavily on the oral language abilities (everyday talking and listening skills) of all parties, most notably those of the young offender, who needs to listen to complex and emotionally charged accounts of the victim's perspective and formulate their own ideas into a coherent narrative that is judged as adequate and authentic by the parties affected by the wrongdoing.

\section{What does 'oral language competence' entail and why is it important?}

OLC refers to the complex two-way process of sending and receiving information via the auditory-verbal (listening and talking) channel. That is, it encompasses the ability to process the spoken language of othersto understand words and the ways in which these are connected grammatically to convey a range of meanings. The meaning behind a speaker's utterances ranges from concrete and literal, through to abstract and sometimes subtly nuanced, with accurate interpretation relying on social inferencing as well as language skills. Anyone who has learned a second language will be familiar with the fact that when listening to native speakers of that language, it may be possible to pick up on key words and determine the gist of a message, but important details are either misunderstood, or missed completely. Competent language users also need to be able to draw on their own vocabulary and knowledge of grammar and social conventions to formulate their own ideas, narratives, wishes and intentions into spoken language that can be understood by others. 
In ideal circumstances, OLC begins to emerge from very early infancy, with key caregivers displaying emotionally warm, consistent engagement with the infant as a basis for reciprocal conversationlike turns that form the basis of early secure attachment, language, cognitive and social skills, and the development of empathy (Snow 2009). Expressive and receptive language skills develop apace in the first five years of life; however, language competence is a lifespan issue, with vocabulary continuing to grow and specialise as education and vocational training unfold. Importantly, in everyday interpersonal exchanges, human beings do not always adhere to a literal script, in which their intended meaning aligns with their stated meaning. In fact, speakers make everyday communication more interesting and entertaining by employing a range of linguistic devices, such as figurative language (idioms, metaphors, analogies), sarcasm (saying the exact opposite of what is meant), humour, puns, irony and paradox. Such devices are known to make everyday communication more challenging and opaque for speakers with identified disabilities (eg those on the autism spectrum, those with an intellectual disability or an acquired brain injury, or those with a specific language impairment). All of these disabilities are overrepresented in youth justice populations (Steinberg, Chung \& Little 2004), giving pause for thought with respect to the linguistic demands of interventions such as restorative justice conferencing.

OLC is the means by which humans form and maintain relationships with others, which is a critical ingredient for mental health (Snow 2009). Evidence indicates that even in the primary school years, children who have language impairments but no other developmental or behavioural difficulties are rated by teachers as performing below peers on impulse control, likeability and prosocial behaviour (Brinton, Fujiki \& Morgan 1999).

However, OLC has a special significance beyond interpersonal functioning. It is also the basis of the transition to literacy in the early school years. Children who commence school with well-developed expressive and receptive language skills are well positioned to make the transition to the more unnatural medium of reading and writing. Many at-risk young people fail to make this transition in the first three years of school and early educational disengagement sets them on a path towards social marginalisation and antisocial behaviour. Unfortunately, such young people are typically identified at school as a consequence of their behavioural difficulties, with underlying languagelearning deficits being undiagnosed (Cohen 2001). These same young people are overrepresented in youth justice statistics (Snow \& Powell 2011a, 2011b).

\section{Research on the oral language skills of young offenders}

Estimates vary as a consequence of methodological differences between studies, but the most conservative estimate, coming from a US study, is that 19 percent of young offenders have language deficits (Larson \& McKinley 1995; Sanger et al. 2001). UK evidence (Bryan 2004) indicates that language deficits are present in 23 to 73 percent of young offenders, depending on the language domain under investigation. In Australian research (Snow \& Powell 2011a, 2008, 2004), it has been shown that approximately one in two young male offenders (on either community-based or custodial orders) is affected by a significant language deficit. Such estimates are in stark contrast to the estimated 14 percent of adolescents in the general population who have language impairments in Australia (McLeod \& McKinnon 2007). It is notable that the language profiles of these young people show wide-ranging difficulties across all aspects of receptive (comprehension) and expressive (talking) skills, including narrative language (the capacity to 'tell the story' of one's own experiences in a way that is logical and coherent to listeners), and the ability to understand and use figurative language. It is important to note, however, that these deficits could not be accounted for on the basis of low IQ.
Further, in a study of incarcerated young offenders (Snow \& Powell 2011a), an association was found between history of interpersonal violence and the presence of a language impairment. This suggests that those young people who commit the most serious offences are more verbally challenged than their counterparts whose convictions are either less serious and/or less frequent. This finding has important implications for restorative conferencing, which is reserved for more serious offences, in order to prevent 'net-widening' associated with diverting those who have committed minor offences to a restorative conference (Richards 2010). It is noted, however, that there is the possibility that the experience of participating in a restorative justice conference could cause stress and anxiety, which could compromise effective verbal communication for some young offenders even in the absence of a language impairment.

Language competence emerges in parallel with other important developmental achievements in the social and cognitive domains. Social cognition refers to the ability to draw inferences about another person's affective state, in real time during an interaction, and to use language and other interpersonal skills to ensure that both parties remain attuned and able to avoid misunderstanding or dissent (Cohen 2001).

An important ingredient for social cognition skills to develop in early life is the ability to both identify and label emotions - others' and one's own. Young people on the autism spectrum and those who have experienced maltreatment (known to be overrepresented in the histories of young offenders) are particularly prone to difficulties in this domain and may in fact display alexithymia-a lack of words for emotions. The extent to which this is present in young offender populations has not been systematically examined; however, the overrepresentation in the youth justice system of young people who are developmentally vulnerable suggests that alexithymia is likely to be present 
in a significant proportion of this population. This notion is consistent with evidence that young offenders are prone to resolve ambiguous social cues via a hostile attribution (Eysenck et al. 2007).

\section{The linguistic demands of restorative justice conferencing}

There is no doubting the seriousness of bringing young offenders face to face with their victim as part of a court-mandated process. It is a high-stakes and highly verbal interchange. However, the medium by which the conference is transacted (auditoryverbal communication) is likely to be one of the most fragile skillsets that the young offender brings to the conference. In order to be an effective conference participant, the young person must be able to attend to and process the language of others, must be able to process both literal and figurative language used by other participants, and must be able to process vocabulary that describes a range of mental states and emotions. At an expressive level, young offenders must be able to draw on vocabulary and narrative skills to provide an account of their actions/motivations and convey remorse and regret with genuineness and authenticity (in the eyes of their victim). Consider too that these processes need to occur in the likely context of elevated stress levels, in and of themselves a threat to successful communication (Maruna \& Mann 2006). It is known that language skills are compromised in at least one in two young offenders, yet it is not known to what extent such deficits impact on their capacity to fulfil the expectations of a restorative justice conference to the satisfaction of victim(s) and other participants (eg police and conference convenors). In fact, a recent study in New South Wales observes that the majority of young offenders' stories in youth justice conferences were brief and were judged to lack sufficient detail (Bolitho 2012).

Like most interventions, restorative justice conferencing is likely to be a better 'fit' for some candidates than others; however, the extent to which language competence acts as an important independent variable with respect to victim satisfaction with the conferencing process has not been previously considered. This is an important gap in restorative justice theory and practice-one that needs to be addressed in order for the intervention to be better tailored to the known heterogeneity of the target population.

One of the more challenging aspects of oral language deficits, irrespective of the population under consideration, is their invisibility. Young offenders with language deficits have an undiagnosed disorder that permeates every aspect of their everyday interpersonal functioning. Yet neither they, nor those with whom they are interacting, have a framework for contextualising responses that can otherwise impress as rude, disinterested, disrespectful, or unmotivated (Snow \& Powell 2011b).

\section{The importance of oral language competence in the restorative justice process}

Restorative justice processes are highly conversational, requiring young offenders to give coherent accounts of their wrongdoing, as well as processing and understanding emotional information conveyed verbally and nonverbally by their victim(s). What, then, should be made of the evidence that in Australia, one in two young offenders has expressive and receptive language skills that fall well below what could be expected on the basis of their age and IQ (Snow \& Powell 2011a, 2008)? What does this evidence mean for a young person's capacity to give an effective account of their wrongdoing and to effectively express their emotions (eg remorse, regret, embarrassment, sorrow)? When difficulties with communication manifest as minimal verbal responses, shoulder shrugs and poor eye contact, what impact does this have on victims', supporters' and police perceptions about the success of the conference? These are important questions that cannot be answered by existing evidence, but demand attention at research, policy and practice levels.
As an illustration of the potential difficulty young offenders (especially males) have in engaging in effective verbal communication during restorative justice conferences, observational and interview data with a number of young offenders who attended a youth justice conference in southeast Queensland during 2005-06 is drawn on. These data were gathered for another project, the Restorative Justice and Reoffending (RJR) project (Hayes, McGee \& Cerruto 2011) and are useful in illustrating key points made herein. The RJR project is a program of qualitative research, which aims to learn how young people know and understand restorative justice interventions and how this knowledge may relate to change in future offending behaviour. Offender-focused observational data were gathered for 68 young offenders attending 48 youth justice conferences. In-depth interview data were gathered for 50 young offenders attending these conferences. Interviews occurred approximately one week following a conference. The observations focused on young offenders' behaviour during the conference and in particular, their verbal and nonverbal communication. The interviews explored how young offenders felt about various aspects of the conferences.

Observers recorded a monologue within 24 hours of their conference observation, recounting with as much detail as possible exactly what occurred during the conference. The transcribed monologue was then used to complete a detailed systematic conference observation protocol. Following is an excerpt from an observation monologue, illustrating the challenges faced by some young offenders in giving an effective account of the circumstances surrounding their offending behaviour.

My general observation with the storytelling phase was that [the conference convenor] had to suggest or assist these young people in telling their story. These three young male offenders appeared rather inarticulate. Lots of one word or one sentence answers and at times, found it difficult to formulate an answer to questions about intent, about circumstance, 
about feelings, what was going through their mind at the time. A lot of answers were 'I don't know', 'I wasn't thinking' etc and [conference convenor] would suggest possible responses to which the young people would agree (RJR case 005a-c).

One of the aims of the in-depth interviews with the young offenders in the RJR project was to determine the extent to which the things young offenders said and did in their conferences reflected what they were thinking and feeling at the time. In Box 1 are excerpts from the interviews with young offenders 005a and 005b (005c declined an interview). These narratives (albeit brief, are consistent with our thesis that these young offenders were challenged by the communication demands they faced) illustrate the paucity of skills with respect to communicating emotions and feelings.

These excerpts (contained in Box 1) illustrate the lack of facility that some young offenders have with verbal communication, as well as their difficulties identifying and describing emotions, whether their own or those of others, in ways that may well be indicative of alexithymia. For example, when asked how he felt when he walked into the room with the other conference participants, 005a replied 'I don't really know'. Similarly, 005b replied 'I don't know really' when asked how meeting the victim made him feel. Also, when asked how hearing the victim's story made him feel, 005b replied, 'no, I don't know'. Furthermore, the often one word or few word answers to interview questions offered by these two young offenders highlights the difficulty some young people have with verbal communication. This was also described recently by researchers conducting fieldwork with young people (Dwyer \& Hayes 2011), who described young people's responses to interview questions as 'the grunt'.
Box 1

\section{Case 005a}

Interviewer: Alright. What did it feel like, actually walking into a room with that many people?

005a: I don't really know. Just looked in, saw them.

Interviewer: Yeah. Okay, before you spoke how did you feel at that point?

005a: Well, actually I was pretty scared.

Interviewer: Okay. Alright, we'll move on from that, okay. When the victim told their story, how did it make you feel? 005a: A little bit better. Relieved. Something like that.

Interviewer: So you can't really remember what she said but you know you felt upset by it. Okay. Did (you) want your mum to attend?

005a: Yeah.

Interviewer: Yeah. Did you agree with what your mum said? Do you remember?

005a: Yeah.

Interviewer: You agreed with it? Sounds like it was hard to hear.

005a: Yeah.

Interviewer: Because it upset you?

005a: Yeah.

Interviewer: But you agreed with it.

005a: Uhuh

Interviewer: So did you ever see that the victim react to what your mum was saying? Or...

005a: No.

Interviewer: Who were you looking at when your mum was talking?

005a: I was talking at my feet at that time.

Interviewer: At your feet. So when you look at your feet how are you normally feeling?

005a: Well I was upset so I was looking at my feet and sort of just trying to not cry.

Interviewer: That's very honest. Thank you...I know that it is hard to talk about that stuff. Isn't it?

005a: Not for me it isn't.

\section{Case 005b}

Interviewer: What about, how did you feel about meeting the victim and other people there?

005b: Pretty sad meeting the victim.

Interviewer: Why were you sad meeting them?

005b: Cause he wanted to find out who actually did the thing and no one told him.

Interviewer: How did you feel about you having to meet him [the victim]?

005b: I don't know really.

Interviewer: Okay. And at the beginning [of the conference], how were you feeling? 005b: Normal.

Interviewer: Didn't feel anything?

005b: No.

Interviewer: So can you tell me about the victim's story and how it made it you feel? 005b: No, I don't know.

Interviewer: Don't know? Didn't it make you feel anything when they were talking?

005b: Oh, made me feel sad for him. So he had to spend a lot of money.

Interviewer: Okay. So you felt sad for him? Did you agree with their story?

005b: Yes.

Interviewer: Yeah? Okay. How did you feel after hearing everyone's stories?

005b: I'm not sure. 


\section{The need for diagnostic 'backstage work'}

Restorative conferences represent a reversal of the axiom that 'actions speak louder than words', because words are the means by which such conferences are transacted and are the key vehicle by which remorse, regret and accountability can be conveyed. Evidence to date suggests that oral language deficits may adversely affect conference outcomes. However, no research to date has examined the impact that oral language deficits have on young offenders' ability to effectively communicate in restorative justice conferences, nor the extent to which this may affect overall satisfaction with conference processes and outcomes. Therefore, it is suggested that there is a pressing need for systematic empirical research on the link between OLC and restorative justice conference outcomes.

In view of the high probability that young offenders entering conferences will have compromised language skills, it is important to develop valid, efficient and systematic measures of OLC so that necessary preconference assessments can be made. With a better understanding of young offenders' language competence, young offenders, victims and other conference participants might be better prepared for the conference process. Ideally, this enhanced preparation will help conference participants develop realistic expectations around young offenders' oral language capacities, improve levels of overall satisfaction for victims and lead to better outcomes; for example, better communication within the conference process, higher compliance rates with agreements and lower reoffending rates.

\section{References}

\section{All URLs correct at July 2013}

Bolitho J 2012. Restorative justice: The ideals and realities of conferencing for young people. Critical Criminology 20(1): 61-78

Bryan K 2004. Preliminary study of the prevalence of speech and language difficulties in young offenders. International Journal of Language and Communication Disorders 39: 391-400
Cohen N 2001. Language impairment and psychopathology in infants, children and adolescents. Thousand Oaks, CA: Sage Publications

Brinton B, Fujiki M \& Morgan M 1999. Withdrawn and sociable behavior of children with language impairment. Language, Speech and Hearing Services in Schools 30: 183-195

Daly K 2002. Sexual assault and restorative justice, in Strang $\mathrm{H}$ \& Braithwaite $\mathrm{J}$ (eds.), Restorative justice and family violence. Cambridge: Cambridge University Press

Dwyer A \& Hayes H 2011. Getting lost in the field: The unpredictable nature of fieldwork with young people, in Bartels $L$ \& Richards K (eds.), Qualitative criminology: Stories from the field. Sydney: Federation Press

Eysenck M, Derakshan N, Santos R \& Calvo M 2007. Anxiety and congitive performance: Attentional control theory. Emotion 7(2): 336-353

Hart D \& Pirc G 2012. Forum sentencing: Using research and experience to improve practice, in Bolitho J, Bruce J \& Mason G (eds.), Restorative justice: Adults and emerging practice. Sydney: Institute of Criminology

Hayes H 2007. Reoffending and restorative justice, in Johnstone G \& Van Ness DW (eds.), Handbook of restorative justice. Portland, OR: Willan: 426-444

Hayes H 2006. Apologies and accounts in youth justice conferences: Reinterpreting research outcomes. Contemporary Justice Review 9(4): 369-385

Hayes $\mathrm{H}$ 2005. Assessing re-offending in restorative justice conferences. Australian and New Zealand Journal of Criminology 38(1): 77-101

Hayes H, McGee T \& Cerruto M 2011. Explaining continuity and change in offending behaviour after a restorative justice conference. Current Issues in Criminal Justice 23(2): 127-143

Larson V \& McKinley N 1995. Language disorders in older students. Eau Claire, Wl: Thinking Publishing

Marshall T 1999. Restorative justice: An overview. London: Home Office
Maruna S \& Mann R 2006. A fundamental attribution error? Rethinking cognitive distortions. Legal and Criminological Psychology 11: 155-177

Maxwell G \& Hayes H 2006. Restorative justice developments in the Pacific region: A comprehensive survey. Contemporary Justice Review 9(2): 127-154

McLeod S \& McKinnon D 2007. Prevalence of communication disorders compared with other learning needs in 14,500 primary and secondary school students. International Journal of Language and Communication Disorders 42(1): 37-59

Milner K 2012. Restorative justice and adult offending: Twelve years of post-sentence practice, in Bolitho J, Bruce J \& Mason G (eds.), Restorative justice: Adults and emerging practice. Sydney: Institute of Criminology

Raye B \& Roberts A 2007. Restorative processes, in Johnstone G \& Ness DV (eds.), Handbook of restorative justice. Devon, UK: Willan Publishing

Richards K 2010. Police-referred restorative justice for juveniles in Australia. Trends \& Issues in Crime and Criminal Justice no. 398. Canberra: Australian Institute of Criminology. http://aic.gov.au/publications/ current\%20series/tandi/381-400/tandi398. html

Sanger D, Creswell J, Dworak J \& Schultz $L$ 2001. Cultural analysis of communication behaviours among juveniles in a correctional facility. Journal of Communication Disorders 33: $31-57$

Smith N \& Weatherburn D 2012. Youth justice conferences versus Children's Court: A comparison of reoffending. Crime and Justice Bulletin 160. Sydney: New South Wales Bureau of Crime Statistics and Research

Snow P 2009. Child maltreatment, mental health and oral language competence: Inviting speech language pathology to the prevention table. International Journal of Speech Language Pathology 11(12): 95-103 
Hennessey Hayes is a Senior Lecturer in the School of Criminology and Criminal Justice at Griffith University.

Pamela Snow is an Associate Professor in the School of Psychology and

Psychiatry at Monash University (Bendigo Regional Clinical School).
General editor, Trends \& issues

in crime and criminal justice series:

Dr Adam M Tomison, Director,

Australian Institute of Criminology

Note: Trends \& issues in crime and criminal justice papers are peer reviewed

For a complete list and the full text of the papers in the Trends \& issues in crime and criminal justice series, visit the AIC website at: http://www.aic.gov.au
ISSN 0817-8542 (Print)

1836-2206 (Online)

(c) Australian Institute of Criminology 2013

GPO Box 2944

Canberra ACT 2601, Australia

Tel: 0262609200

Fax: 0262609299

Disclaimer: This research paper does not necessarily reflect the policy position of the Australian Government
Snow P \& Powell M 2011a. Oral language competence in incarcerated young offenders: Links with offending severity. International Journal of Speech Language Pathology 13(6): 480-489

Snow P \& Powell M 2011b. Youth (in)justice: Oral language competence in early life and risk for engagement in antisocial behaviour in adolescence. Trends \& Issues in Crime and Criminal Justice no. 435. Canberra: Australian Institute of Criminology. http:// aic.gov.au/publications/current\%20series/ tandi/421-440/tandi435.html
Snow P \& Powell M 2008. Oral language competence, social skills, and high risk boys: What are juvenile offenders trying to tell us? Children and Society 22: 16-28

Snow P \& Powell M 2004. Developmental language disorders and adolescent risk: A public-health advocacy role for speech pathologists? International Journal of Speech Language Pathology 6(4): 221-229
Steinberg L, Chung H \& Little M 2004. Reentry of young offenders from the justice system: A developmental perspective. Youth Violence and Juvenile Justice 2(1): 21 